\title{
Terminação de novilhos em pastagem de aveia branca consorciada com leguminosa ou associada à suplementação energética
}

\author{
[Finishing steers on oat pasture intercropped with legumes or receiving \\ energetic supplementation] \\ M.M.G. Hirai ${ }^{1}$, L.F.G. Menezes ${ }^{2 *}$, F. Kuss ${ }^{2}$, W. Paris ${ }^{2}$, E. Lisbinski ${ }^{1}$, O.N. Oliveira ${ }^{1}$, \\ D. Nazário ${ }^{1}$, G.R. Schimtz \\ ${ }^{1}$ Aluno de pós-graduação - Universidade Tecnológica Federal do Paraná - Dois Vizinhos, PR \\ ${ }^{2}$ Universidade Tecnológica Federal do Paraná - Dois Vizinhos, PR \\ RESUMO
}

\begin{abstract}
O objetivo do experimento foi avaliar a associação da ervilhaca (Vica sativa) ou da suplementação energética em pastagem de aveia branca (Avena sativa) sobre o desempenho de novilhos de corte na fase de terminação. Foram utilizados 18 novilhos castrados, $1 / 4$ Marchegiana $1 / 4$ Aberdeen Angus $2 / 4$ Nelore, com peso vivo e idade média de 360kg e 19 meses, respectivamente, divididos em três tratamentos: pastagem de aveia branca, pastagem de aveia branca consorciada com ervilhaca e pastagem de aveia branca com suplementação energética (milho grão triturado, $1 \%$ do peso vivo por dia, na matéria seca). O delineamento experimental utilizado foi o de blocos ao acaso com três tratamentos e três repetições. Houve interação significativa entre o período de avaliação e os tratamentos para participação do componente folha da aveia na pastagem. A participação da ervilhaca aumentou no decorrer do experimento de $3,51 \%$ para $12,21 \%$ consequentemente a participação da aveia diminuiu no decorrer do experimento. Não houve diferença significativa $(\mathrm{P}>0,05)$ para massa de forragem, carga animal, oferta de forragem e taxa de acúmulo diário entre os tratamentos. Os animais que receberam suplementação apresentaram maior $(\mathrm{P}<0,05)$ ganho de peso médio diário $(1,08 \mathrm{~kg} / \mathrm{dia})$, ganho de peso vivo por hectare $(4,47 \mathrm{~kg} / \mathrm{ha} / \mathrm{dia})$ e ganho de peso vivo total $(242,82 \mathrm{~kg})$ em comparação com aqueles que receberam somente a pastagem de aveia $(0,68 \mathrm{~kg} ; 2,50 \mathrm{~kg} / \mathrm{ha} / \mathrm{dia} ; 123,49 \mathrm{~kg}$, respectivamente). Já os animais que permaneceram em pastagem consorciada de aveia e ervilhaca apresentaram resultados intermediários $(0,89 \mathrm{~kg} / \mathrm{dia} ; 2,99 \mathrm{~kg} / \mathrm{ha} / \mathrm{dia}$ e $154,26 \mathrm{~kg}$, respectivamente). O melhor peso final foi para o tratamento com suplementação $(424,44 \mathrm{~kg})$. A suplementação energética em pastagem de aveia branca apresentou melhores resultados de desempenho animal. No entanto, a consorciação de aveia branca e ervilhaca é uma alternativa quando o suplemento (grão de milho) está com um custo elevado, uma vez que o desempenho, apesar de menor, não foi diferente dos animais suplementados.
\end{abstract}

Palavras-chave: Avena sativa L., carga animal, massa de forragem, ervilhaca

\begin{abstract}
The aim of this experiment was to evaluate the association of vetch (Vica sativa) or energy supplementation in oat (Avena sativa) on the performance of steers in the finishing phase. The experiment was performed in 18 steers, quarter Marchegiana, quarter Aberdeen Angus and $2 /{ }_{4}$ Nellore genetic groups, with the live weight and age of $360 \mathrm{~kg}$ and 19 months, respectively, divided into three treatments: pasture white oat, pasture white oat intercropped with vetch and oat pasture with energetic supplementation with the basis of ground corn (1\% body weight per day in dry matter). The experimental design was a randomized block design with three treatments and three replications. The interaction was observed by the period of evaluation and treatments for the participation of oat leaf in grassland. The participation of vetches increased in the course of the experiment from $3.51 \%$ to $12.21 \%$ as opposed to the participation of oat, which decreased in the course of the experiment in all treatments. No significant difference $(P>0.05)$ was found for the forage mass, stoking rate, forage offer and rate of daily accumulation between treatments. The animals that received supplementation showed higher
\end{abstract}

Recebido em 8 de agosto de 2013

Aceito em 10 de abril de 2015

*Autor para correspondência (corresponding author)

E-mail: luismenezes@utfpr.edu.br 
$(P<0.05)$ average daily weight gain $(1.08 \mathrm{~kg} /$ day), live weight gain for ha $(4.47 \mathrm{~kg} / \mathrm{ha} /$ day) and total live weight gain $(242.82 \mathrm{~kg})$ compared with those animals that received only oat $(0.68 \mathrm{~kg}, 2.50 \mathrm{~kg} / \mathrm{ha} / \mathrm{day} ; 123.49 \mathrm{~kg}$, respectively). While the animals that have remained in pasture with oat and vetch showed intermediate results $(0.89 \mathrm{~kg} /$ day, $2.99 \mathrm{~kg} / \mathrm{ha} /$ day and $154.26 \mathrm{~kg}$, respectively) the final weight was better in the treatment with supplementation $(424.44 \mathrm{~kg})$. The energy supplementation with oat pasture is presented as the best alternative to improve animal performance. Nevertheless, the oat plus vetch is an alternative when the supplement (corn grain) has a high cost, once the animal performance was lower, but it was not different from the energetic supplementation.

Keywords: Avena sativa L., stoking rate, the forage mass, vetch

\section{INTRODUÇÃO}

Na pecuária de corte nacional, devido aos fatores climáticos e à grande extensão territorial, existem vários sistemas de terminação. $\mathrm{Na}$ maioria das regiões, os bovinos são terminados quase exclusivamente em sistemas baseados em pastagens tropicais e subtropicais, as quais apresentam crescimento acentuado na primavera e no verão, reduzido no outono e, no inverno, paralisação do crescimento. Diferentemente de outras regiões do Brasil, que sofrem com os fatores climáticos, sobretudo com o déficit hídrico no outono e no inverno, os quais prejudicam a produção de pastagens tropicais, na região Sul a baixa produção de forrageiras no período crítico está mais relacionada com a queda de temperatura (Hellbrugge et al., 2008). Em decorrência dessa característica climática, o uso de pastagens anuais de clima temperado pode ser uma das alternativas viáveis para a produção de bovinos de corte na região (Menezes et al., 2009).

Entre as diversas opções de pastagens de clima temperado disponíveis para suprir alimento de boa qualidade para o período de escassez de forragem, a aveia é uma das gramíneas mais utilizadas, de forma isolada ou associada com outras gramíneas ou leguminosas. A aveia apresenta elevados níveis de proteína, alta digestibilidade e boa palatabilidade (Grise et al., 2002). Além dos bons ganhos de peso que essa gramínea proporciona, ela ainda possibilita que os pecuaristas comercializem os animais no período de entressafra, aumentando o resultado financeiro da atividade (Aguinaga et al., 2006).

A consorciação de gramíneas com leguminosas de clima temperado constitui opção importante para a produção animal pelos bons rendimentos $\mathrm{e}$ pela qualidade de forragem dessas espécies, proporcionando altas produções por área, maior período de ocupação da pastagem e mantendo o ritmo de engorda dos animais durante o período crítico de produção (Grise et al., 2002). Esse incremento de produção se deve ao ciclo mais tardio e longo da leguminosa em comparação com a aveia branca. Além disso, a utilização de leguminosas pode trazer benefícios tanto para a pastagem quanto para o solo em razão da fixação biológica de nitrogênio, reduzindo a dependência de adubação química (Barcellos et al., 2008).

Outra alternativa na alimentação de bovinos em fase de terminação em pastagens temperadas é a suplementação energética, que ajuda no balanço de nutrientes e aumenta o consumo total de matéria seca, uma vez que a aveia tem baixo teor de matéria seca, podendo haver limitação física do rúmen (Hellbrugge et al., 2008). De acordo com Paulino et al. (2005), os suplementos energéticos geralmente possuem maior digestibilidade da matéria seca que as forragens, de modo que o fornecimento desses suplementos geralmente melhora a digestibilidade da matéria seca da dieta total. Com a substituição de parte do consumo da pastagem pelo consumo de suplemento, é possível elevar a carga animal por área, sem redução do ganho individual (Hellbrugge et al., 2008).

O presente trabalho foi conduzido para avaliar a influência da consorciação da ervilhaca em pastagem de aveia branca e a associação da suplementação energética com a pastagem de aveia branca sobre o desempenho de novilhos de corte na fase de terminação.

\section{MATERIAL E MÉTODOS}

O experimento foi conduzido na Universidade Tecnológica Federal do Paraná - Câmpus Dois Vizinhos, no período compreendido entre maio e agosto de 2011. A região é fisiograficamente chamada de terceiro planalto paranaense, com 
altitude de $520 \mathrm{~m}$, latitude de $25^{\circ} 44^{\prime \prime}$ sul e longitude de $53^{\circ} 04^{\prime \prime}$ oeste, sendo o clima do tipo subtropical úmido mesotérmico (Cfa e $\mathrm{Cfb}$ ), segundo a classificação de Köppen. O solo local é o tipo latossolo vermelho distroférrico e o terreno apresenta em torno de $5 \%$ de declividade média (Embrapa-CNPS, 2006). O índice de precipitação pluviométrica e as temperaturas máxima e mínima durante o período experimental, coletados na Estação Meteorológica de Dois Vizinhos - PR apresentam-se na Fig. 1.

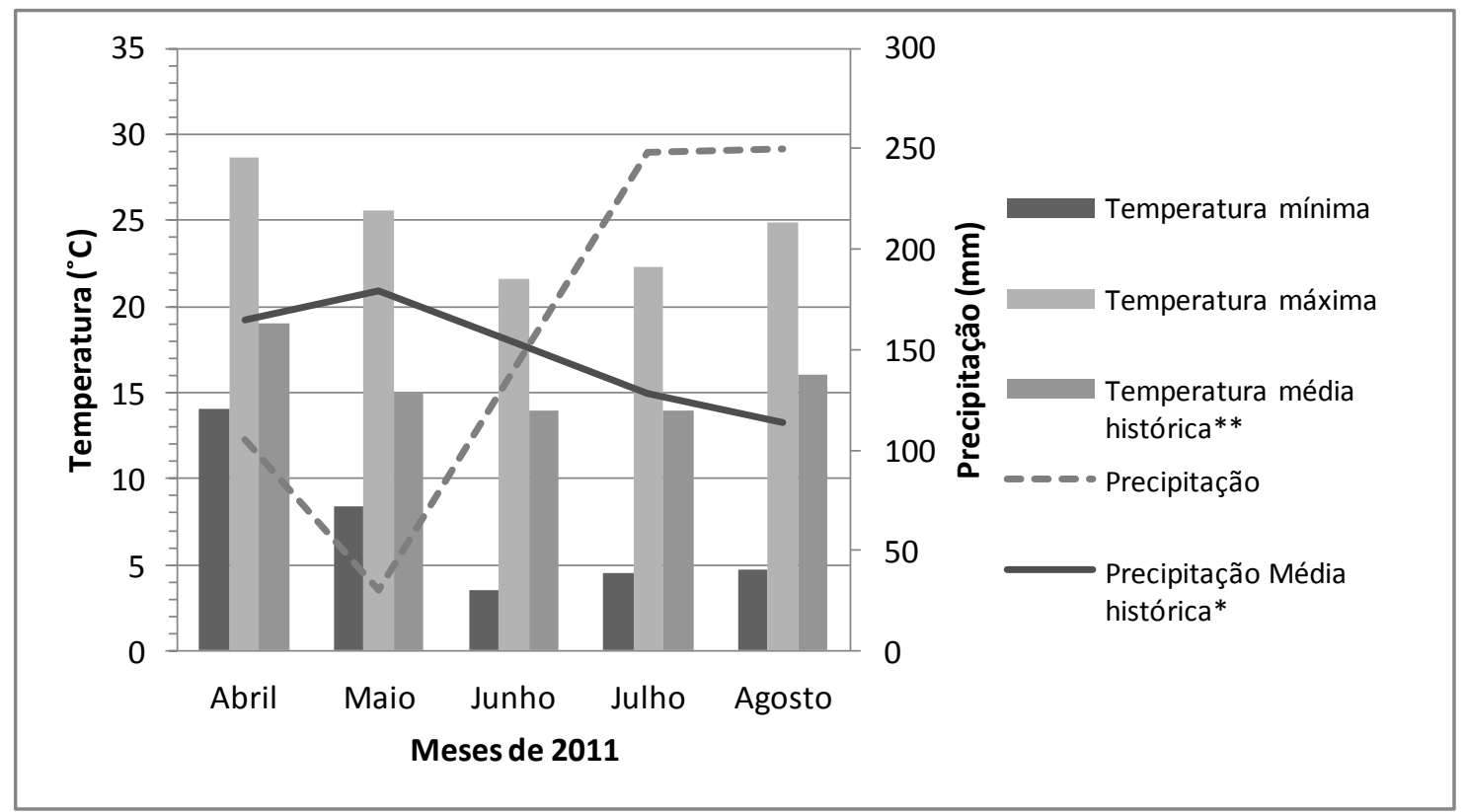

Figura 1. Médias mensais de temperaturas mínima e máxima e precipitação pluviométrica durante o período experimental em Dois Vizinhos, Paraná, 2011.

* Média para Dois Vizinhos de 1976 a 2006 (Possenti et al., 2007).

** Média dos últimos 20 anos para a região sudoeste do PR (IAPAR, 2014).

A área experimental utilizada foi de 6,3ha, dividida em nove piquetes com área média de 0,7 ha/piquete, e mais dois piquetes adicionais adjacentes para manutenção dos animais reguladores. Foram implantados seis piquetes de pastagem de aveia branca (Avena sativa L.), semeados a lanço com $80 \mathrm{~kg}$ de sementes viáveis por hectare, e três piquetes de pastagem de aveia branca associada com ervilhaca cultivar SS Ametista (Vica sativa), semeados a lanço com $80 \mathrm{~kg}$ de sementes viáveis de aveia branca (Paulino e Carvalho, 2004) e 50kg de sementes viáveis de ervilhaca por hectare (Dall'agnol e Scheffer-Basso, 2004) com posterior gradagem, em 12 de abril de 2011. A área era utilizada há dois anos como pastagem cultivada (inverno=aveia; verão=milheto), precedida por mais de 10 anos como lavoura de milho ou soja. A análise de solo indicou $\mathrm{pH}(\mathrm{CaCl} 2)=5,4 ; \mathrm{MO}$ $($ gkg-1) $=40,21 ; \mathrm{P}(\mathrm{mg} \mathrm{dm}-3)=23,83 ; \mathrm{K}(\mathrm{cmol} \mathrm{c}$ $\mathrm{dm}-3)=0,50 ; \mathrm{Ca}(\mathrm{cmol} \mathrm{c} \mathrm{dm-3)}=7,24 ; \mathrm{Mg}$ $(\mathrm{cmol} \mathrm{c} \mathrm{dm-3)}=3,27 ; \mathrm{H}+\mathrm{Al}(\mathrm{cmol} \mathrm{c} \mathrm{dm-3})=$ 4,61; SB $(\mathrm{cmol} \mathrm{c} \mathrm{dm-3)} \mathrm{=11,01;} \mathrm{T}(\mathrm{cmol} \mathrm{c} \mathrm{dm-}$ $3)=15,62$ e $\mathrm{V}(\%)=70,49$. A adubação estabelecida foi de $250 \mathrm{~kg}$ da fórmula $08-20-10$ (N-P-K) no plantio, conforme recomendação de SCBS (2004). Na adubação de cobertura, foram utilizados $40 \mathrm{~kg}$ de nitrogênio por hectare na forma de ureia, divididos em duas aplicações.

Foram utilizados 30 novilhos castrados, do grupo genético $1 / 4$ Marchegiana $1 / 4$ Aberdeen Angus $2 / 4$ Nelore, com peso vivo médio inicial de aproximadamente $360 \mathrm{~kg}$ e idade média inicial de 19 meses. Em cada repetição, foram utilizados dois animais testes e um número variável de animais reguladores.

Durante 75 dias (14 dias de adaptação e 61 de avaliação), os novilhos foram divididos em três diferentes tratamentos: no tratamento aveia, os animais permaneceram somente na pastagem de 
aveia branca; no tratamento aveia + ervilhaca, os animais permaneceram na pastagem de aveia branca consorciada com ervilhaca; e no tratamento aveia + suplementação, os animais permaneceram em pastagem de aveia branca associada com suplementação energética à base de milho triturado na quantidade de $1 \%$ do peso vivo, com base na matéria seca.

As avaliações das pastagens foram realizadas a cada 21 dias, registrando-se a massa de forragem pela técnica de dupla amostragem proposta por Wilm et al. (1944). A taxa de acúmulo de forragem foi determinada utilizando-se gaiolas de exclusão no piquete. A cada período de 21 dias, as gaiolas foram posicionadas em pontos representativos da altura média da pastagem, com massa e composição morfológica semelhantes às áreas sob pastejo. As massas de matéria seca, dentro e fora da gaiola, foram obtidas por corte rente ao solo, depois de cada corte as gaiolas foram realocadas em outros pontos dos piquetes seguindo a mesma metodologia. $\mathrm{O}$ acúmulo de forragem $(\mathrm{kg} / \mathrm{ha}$ de matéria seca) foi obtido pela diferença entre as massas de forragem observadas dentro e fora da gaiola. Para a estimativa da taxa de acúmulo diário de forragem $(\mathrm{kg} / \mathrm{ha} / \mathrm{dia})$, dividiu-se o acúmulo de forragem pelo intervalo de dias das avaliações.
O sistema de pastejo empregado foi o pastejo contínuo com lotação variável, por meio da técnica put and take descrita por Mott e Lucas (1952), utilizando-se animais reguladores de maneira a manter a pastagem com a oferta desejada. A carga animal média por período foi calculada pelo somatório do peso médio de cada animal multiplicado pelo número de dias que este permaneceu na pastagem, dividido pelo número de dias do período. A oferta de forragem pretendida de $9 \%$ foi calculada pela razão entre a disponibilidade diária de forragem da pastagem e a carga animal utilizada em cada período de avaliação. A cada avaliação, foram destinadas amostras para a separação botânica, que determinou a porcentagem de folha, colmo, material senescente, plantas invasoras e ervilhaca (nos piquetes com tratamento com leguminosa).

Para a determinação do valor nutritivo (Tab. 1), foram retiradas amostras de forragem e do suplemento. Nas amostras coletadas, foram determinados os teores de fibra em detergente neutro (FDN), fibra em detergente ácido (FDA) e lignina (LDA), utilizando-se a técnica de Goering e Van Soest (1970). O teor de nutrientes digestíveis totais (NDT) foi calculado de acordo com a equação proposta por Weiss et al. (1992). Para as análises de matéria seca (MS), extrato etéreo (EE) e proteína bruta (PB), foram utilizadas as técnicas descritas por Silva e Queiroz (2006).

Tabela 1. Composição bromatológica da pastagem e do suplemento

\begin{tabular}{|c|c|c|c|c|c|c|c|}
\hline \multirow{3}{*}{ Composição } & \multicolumn{3}{|c|}{ Componentes } & & \multicolumn{3}{|c|}{ Amostras compostas da pastagem } \\
\hline & \multirow[b]{2}{*}{ Milho } & \multicolumn{2}{|c|}{ Pastagem de aveia } & \multirow[b]{2}{*}{ Ervilhaca } & \multicolumn{3}{|c|}{ Tratamento } \\
\hline & & Folha & Colmo & & Aveia & $\begin{array}{l}\text { Aveia + } \\
\text { ervilhaca }\end{array}$ & $\begin{array}{c}\text { Aveia + } \\
\text { suplemento }\end{array}$ \\
\hline Matéria seca \% & 81,48 & 14,95 & 11,33 & 17,93 & 14,33 & 14,44 & 13,75 \\
\hline FDN*, \% & 9,00 & 43,31 & 60,94 & 37,18 & 51,00 & 58,00 & 53,72 \\
\hline $\mathrm{FDA}^{*}, \%$ & 7,74 & 27,03 & 32,79 & 26,41 & 30,79 & 32,43 & 30,85 \\
\hline Proteína bruta \% & 8,48 & 23,76 & 15,15 & 24,93 & 17,99 & 18,00 & 18,63 \\
\hline Extrato etéreo \% & 3,79 & 2,68 & 1,39 & 3,13 & 2,97 & 2,03 & 2,33 \\
\hline Lignina $\%$ & 1,69 & 5,85 & 5,96 & 4,00 & 4,70 & 4,64 & 7,70 \\
\hline NIDA, \%* & 3,19 & 1,06 & 0,31 & 1,47 & 0,61 & 0,56 & 0,52 \\
\hline NDT, \%* & 81,00 & 58,53 & 50,34 & 66,00 & 57,73 & 50,49 & 51,80 \\
\hline
\end{tabular}

*FDN - fibra em detergente neutro; FDA - fibra em detergente ácido; NIDA - nitrogênio insolúvel em detergente ácido; NDT - nutrientes digestíveis totais (\%).

Para a avaliação do ganho de peso médio diário (GMD), foram realizadas pesagens em intervalos de 21 dias nos dois primeiros períodos e de 20 dias no último, após período de jejum alimentar e hídrico de 14 horas. O GMD dos animais foi obtido pela diferença entre os pesos final e inicial dos animais testers, em cada período experimental, dividida pelo número de dias do período de pastejo. O ganho de peso vivo por hectare (GPV/ha) foi obtido multiplicando-se o 
ganho de peso médio dos animais testers pelo número de dias multiplicado pelo número de animais por hectare em cada período.

O delineamento experimental utilizado foi o inteiramente ao acaso, com três tratamentos e três repetições. A análise de variância foi realizada com auxílio do programa SAS (2000), e as médias comparadas pelo teste $t$ de Student a $5 \%$ de probabilidade.

\section{RESULTADOS E DISCUSSÃO}

Houve interação significativa entre o período de avaliação e os tratamentos para participação da aveia na pastagem (Tab. 2). Na pastagem de aveia consorciada com ervilhaca, a presença da aveia foi diminuindo $(\mathrm{P}<0,05)$ com o avanço dos períodos, enquanto nos demais tratamentos não houve variação entre os períodos. Essa variação se deve ao aumento da participação da ervilhaca em relação à aveia.

Tabela 2. Composição botânica de pastagem de aveia branca solteira, consorciada com ervilhaca ou associada à suplementação energética, de acordo com o período de avaliação

\begin{tabular}{|c|c|c|c|c|c|}
\hline \multirow[b]{2}{*}{ Tratamento } & \multicolumn{3}{|c|}{ Período } & \multirow[b]{2}{*}{$\begin{array}{c}\text { Média } \\
\text { Tratamento }\end{array}$} & \multirow[b]{2}{*}{ EPM } \\
\hline & $\begin{array}{c}28 / 05 / 11 \\
a \\
12 / 06 / 11\end{array}$ & $\begin{array}{c}12 / 06 / 11 \\
a \\
05 / 07 / 11\end{array}$ & $\begin{array}{c}25 / 07 / 11 \\
a \\
27 / 07 / 11\end{array}$ & & \\
\hline \multicolumn{6}{|c|}{$\%$ Aveia } \\
\hline Aveia & $90,09^{\mathrm{ab}}$ & $89,70^{\mathrm{abc}}$ & $84,78^{\mathrm{bc}}$ & 88,19 & 2,71 \\
\hline Aveia+ervilhaca & $83,99^{\mathrm{bc}}$ & $67,41^{\mathrm{d}}$ & $49,76^{\mathrm{e}}$ & 67,05 & 2,71 \\
\hline Aveia+suplementação & $95,75^{\mathrm{a}}$ & $90,61^{\mathrm{ab}}$ & $81,21^{\mathrm{ab}}$ & 89,19 & 2,71 \\
\hline Média & 89,94 & 82,57 & 71,91 & & 1,56 \\
\hline \multicolumn{6}{|c|}{ \% Ervilhaca } \\
\hline Ervilhaca & $3,51^{\mathrm{c}}$ & $7,35^{\mathrm{b}}$ & $12,21^{\mathrm{a}}$ & 7,69 & 0,90 \\
\hline \multicolumn{6}{|c|}{ \% Relação folha/colmo da aveia* } \\
\hline Aveia & 1,78 & 1,04 & 0,85 & 1,22 & 0,20 \\
\hline Aveia+ervilhaca & 1,59 & 0,81 & 0,75 & 1,05 & 0,20 \\
\hline Aveia+suplementação & 1,92 & 1,23 & 0,78 & 1,31 & 0,20 \\
\hline Média & $1,76^{\mathrm{a}}$ & $1,03^{\mathrm{b}}$ & $0,79^{\mathrm{b}}$ & & 0,11 \\
\hline \multicolumn{6}{|c|}{$\%$ Outros } \\
\hline Aveia & 5,30 & 1,27 & 0,96 & 2,51 & 1,39 \\
\hline Aveia+ervilhaca & 1,07 & 0,45 & 0,41 & 0,64 & 1,39 \\
\hline Aveia+suplementação & 0,49 & 2,43 & 2,43 & 1,78 & 1,39 \\
\hline Média & 2,29 & 1,38 & 1,27 & & 0,80 \\
\hline \multicolumn{6}{|c|}{$\%$ Material senescente } \\
\hline Aveia & 4,61 & 9,18 & 14,39 & 9,39 & 2,57 \\
\hline Aveia+ervilhaca & 4,39 & 10,80 & 13,20 & 9,22 & 2,57 \\
\hline Aveia+suplementação & 3,76 & 7,26 & 16,66 & 9,22 & 2,57 \\
\hline Média & $4,25^{\mathrm{c}}$ & $8,84^{\mathrm{b}}$ & $14,75^{\mathrm{a}}$ & & 1,48 \\
\hline
\end{tabular}

Médias seguidas por letras diferentes, na mesma linha, diferem entre si pelo teste " $\mathrm{t}$ " $(\mathrm{P}<0,05)$.

A participação da ervilhaca foi, em média, de $7,69 \%$, aumentando no decorrer do período de utilização da pastagem, ao contrário da aveia, que, em todos os tratamentos, diminuiu no decorrer do experimento. A menor participação da ervilhaca no primeiro período se deve ao fato de o crescimento da aveia ser maior. As espécies leguminosas de inverno possuem capacidade de fixar nitrogênio atmosférico pela simbiose com bactérias específicas, o que eleva a disponibilidade desse nutriente no solo. Segundo
Harris (1990), a leguminosa cresce bem unicamente, quando o fornecimento de nitrogênio é insuficiente para um crescimento máximo das gramíneas. A competição por luz, água e outros nutrientes entre a aveia e a ervilhaca pode ter colaborado para a baixa participação da ervilhaca no início do experimento (Frame e Newbould, 1986). No decorrer do tempo, entretanto, o avanço do ciclo da aveia e a ausência de competição por luminosidade e nutrientes possibilitaram o 
desenvolvimento da ervilhaca. Outra explicação pode ser a preferência dos animais pela gramínea em detrimento da leguminosa. Segundo Barcellos et al. (2008), a maioria das leguminosas apresenta baixa aceitabilidade pelos bovinos, e o efeito mais marcante da leguminosa de baixa palatabilidade na dieta do animal darse-á no final do ciclo da gramínea.

Não houve diferença significativa na participação de outras espécies (plantas invasoras) entre os tratamentos. Durante o experimento, houve um controle mecânico sistemático das plantas invasoras, evitando seu aumento em todos os piquetes e a participação na alimentação dos animais.

A porcentagem de material senescente aumentou significativamente $(\mathrm{P}<0,05)$ conforme o pasto de aveia atingia a maturidade fisiológica. Esse aumento de material senescente pode dificultar o pastejo dos animais, ao diminuir a oferta e a altura da forragem, reduzir o consumo dos animais e interferir em seu desenvolvimento (Almeida et al., 2000).

O primeiro período apresentou melhor relação folha/colmo $(1,76)$, diferindo significativamente $(\mathrm{P}<0,05)$ do segundo $(1,03)$ e do terceiro período $(0,79)$. As gramíneas de clima temperado apresentam elevada densidade de folhas quando são jovens, apresentando maior valor nutritivo. Porém, com o avanço do ciclo de desenvolvimento, aumenta-se a participação de colmo e material senescente, consequentemente, reduz-se o valor nutritivo da forragem (Macari et al., 2006).

Não houve interação significativa entre tratamentos e período. Portanto, serão apresentados e discutidos apenas os tratamentos.

Não houve diferença $(\mathrm{P}>0,05)$ para massa de forragem, carga animal, oferta de forragem e taxa de acúmulo diário entre os tratamentos (Tab. 3). A massa de forragem média da aveia $(841,50 \mathrm{~kg}$ de MS), aveia consorciada com ervilhaca $(802,70 \mathrm{~kg}$ de MS) e aveia com suplementação $(1.034,90 \mathrm{~kg}$ de MS) ficou abaixo do pretendido. Essa baixa massa de forragem se deve principalmente à baixa precipitação entre os meses de abril e maio (Fig. 1), o que prejudicou o desenvolvimento inicial da pastagem. Com isso, a oferta de forragem preconizada de 9 a $10 \%$ não foi alcançada, assim a oferta de forragem real encontrada foi, em média, de $7 \%$.

Segundo Mott (1960), a massa de forragem para pastagem de clima temperado deve estar entre 1.200 e $1.600 \mathrm{~kg}$ de MS/ha; valores abaixo desses níveis podem comprometer o desempenho animal. Almeida et al. (2000) preconizam que a oferta de forragem deve ser três a quatro vezes maior que o consumo estimado dos bovinos. Essa oferta de forragem possibilita uma melhor seleção do alimento.

Tab. 3. Características produtivas de pastagem de aveia branca solteira, consorciada com ervilhaca ou associada à suplementação energética

\begin{tabular}{lcccc} 
& \multicolumn{3}{c}{ Tratamento } & EPM \\
\cline { 2 - 4 } Variável & Aveia & $\begin{array}{c}\text { Aveia }+ \\
\text { ervilhaca }\end{array}$ & $\begin{array}{c}\text { Aveia }+ \\
\text { suplementação }\end{array}$ & EPn \\
\hline Massa de forragem (kg de MS) & 841,50 & 802,70 & $1.034,90$ & 71,52 \\
Carga animal (kg de PV) & $1.189,90$ & $1.412,90$ & $1.478,70$ & 109,37 \\
Oferta de forragem (\%) & 7,90 & 6,68 & 6,60 & 1,21 \\
Taxa de acúmulo diário (kg de MS) & 79,55 & 80,54 & 79,76 & 10,79 \\
\hline
\end{tabular}

A carga animal/ha foi muito semelhante entre os tratamentos de aveia consorciada com leguminosa $(1.412,90 \mathrm{~kg})$ e aveia com suplementação $(1.478,70 \mathrm{~kg})$. Rocha et al. (2003), ao estudarem o efeito da adubação nitrogenada em comparação com a suplementação em pastagem de aveia e azevém ou o consórcio com trevo vesiculoso (Trifolium vesiculosum Savi), observaram carga animal média de $1.360 \mathrm{~kg}$ de $\mathrm{PV} / \mathrm{ha}$, bastante próxima do presente experimento. No entanto, esses autores observaram superioridade de $22,9 \%$ na carga animal nas pastagens associadas com suplementação em relação àquela consorciada com leguminosa (trevo vesiculoso). Os autores sugerem que essa resposta foi devido ao efeito substitutivo do concentrado sobre a pastagem..

A taxa de acúmulo diário foi semelhante entre os tratamentos. Esperava-se que essa taxa fosse 
maior para o tratamento de aveia consorciada com ervilhaca, pela capacidade de a leguminosa, em simbiose com bactérias fixadoras de nitrogênio atmosférico, contribuir com o aumento da produção. Barcellos et al. (2008) citam que quanto mais pobre o solo, maior será a proporção de $\mathrm{N}$ oriundo da fixação biológica. Observa-se, na análise, que o solo apresentou uma boa qualidade $(\mathrm{MO}=4,02 \%)$. Isso pode ser visualizado pelas taxas de crescimento, que foram bastante elevadas $(79,95 \mathrm{~kg} / \mathrm{dia}, \quad \mathrm{em}$ média). Rocha et al. (2003) observaram taxas de acúmulo de $40,4 \mathrm{~kg}$ de MS/ha quando consorciaram aveia, azevém e trevo vesiculoso.

O peso vivo médio final dos animais (Tab. 4) foi superior $(\mathrm{P}<0,05)$ para aqueles que receberam suplementação com o grão de milho moído $(424,44 \mathrm{~kg})$. O maior peso foi reflexo do melhor desempenho desses animais. Esse resultado é explicado pelo fato de os animais estarem em fase de terminação, quando a exigência de PB é mais baixa e a necessidade de energia se torna maior para o processo de acabamento de gorduras de marmoreio e subcutâneas. Segundo Santos et al. (2001), com o aumento de degradabilidade da proteína dietética, maior será a produção de amônia ruminal, acarretando maiores perdas de nitrogênio na urina e nas fezes. Consequentemente, os armazenamentos de energia líquida de mantença, crescimento e reserva de gordura acabam sendo menores pelo excesso de proteína em sua alimentação, resultando em desempenho animal mais baixo (Wright, 2013). Dierking et al. (2010) comentaram que nem sempre uma pastagem de qualidade superior pode ser a melhor alternativa para se obter o melhor desempenho animal, sendo necessário o uso de uma suplementação com alto teor de energia em sua alimentação.

O ganho de peso médio diário foi superior nos animais que receberam suplementação $(1,08 \mathrm{~kg})$ quando comparados com os animais do tratamento de pastagem de aveia solteira $(0,68 \mathrm{~kg})$. O milho triturado apresentou maior proporção de matéria seca e NDT em relação aos demais alimentos (Tab. 1), o que possibilitou balancear melhor os nutrientes, principalmente considerando que os animais na fase de terminação necessitam de maior aporte energético para se desenvolverem. A composição do ganho de peso de animais na fase de terminação passa a ser predominantemente por tecido adiposo, o qual, em termos de energia consumida por quilo de tecido depositado, é menos eficiente que o tecido muscular (Alves, 2003).

Tab. 4. Desempenho de novilhos terminados em pastagem de aveia branca solteira, consorciada com ervilhaca ou associada à suplementação energética

\begin{tabular}{|c|c|c|c|c|}
\hline \multirow[b]{2}{*}{ Variável } & \multicolumn{3}{|c|}{ Tratamento } & \multirow[b]{2}{*}{ EPM } \\
\hline & Aveia & $\begin{array}{l}\text { Aveia + } \\
\text { ervilhaca }\end{array}$ & $\begin{array}{c}\text { Aveia + } \\
\text { suplementação }\end{array}$ & \\
\hline Peso inicial $(\mathrm{kg}) *$ & 364,70 & 369,20 & 368,70 & - \\
\hline Peso final $(\mathrm{kg})$ & $408,89 b$ & $411,15 b$ & $424,44 a$ & 5,18 \\
\hline Ganho de peso médio diário ( $\mathrm{kg} / \mathrm{dia})$ & $0,68 b$ & $0,89 \mathrm{ab}$ & $1,08 \mathrm{a}$ & 0,75 \\
\hline $\begin{array}{l}\text { Ganho de peso vivo diário } \\
\text { (kg/ha/dia) }\end{array}$ & $2,09 \mathrm{c}$ & $3,20 b$ & $4,00 \mathrm{a}$ & 49,30 \\
\hline Ganho de peso vivo total $(\mathrm{kg} / \mathrm{ha})$ & $128,00 \mathrm{c}$ & $195,30 \mathrm{~b}$ & $244,27 \mathrm{a}$ & 34,04 \\
\hline
\end{tabular}

Médias seguidas por letras diferentes, na mesma linha, diferem entre si pelo teste " $\mathrm{t}$ " $(\mathrm{P}<0,05)$. *Essa característica não foi analisada estatisticamente.

Os animais que consumiram a pastagem de aveia consorciada com ervilhaca apresentaram GMD $(0,89 \mathrm{~kg} / \mathrm{dia})$ semelhante aos que receberam suplementação. Segundo Laidlawe Teuber (2001), o valor nutritivo e o consumo mais elevado das leguminosas em relação às gramíneas é consequência de uma série de fatores, que incluem maior taxa de quebra das partículas e digestão ruminal, maior quantidade de nitrogênio não amoniacal atingindo o intestino delgado e maior eficiência da utilização da energia. No presente experimento, essa maior eficiência não foi verificada, já que o GMD dos animais que consumiram ervilhaca foi semelhante $(\mathrm{P}>0,05)$ ao daqueles que consumiram apenas pastagem de aveia. Resultados semelhantes foram encontrados por Rocha et al. (2003). 
O ganho de peso médio diário dos animais em todos os tratamentos foi menor quando comparado com os da literatura. Moreira et al. (2005), que estudaram o desempenho de bovino na fase de terminação em pastagem de aveia preta com e sem suplementação, relataram que os animais mantidos apenas na pastagem de aveia apresentaram ganho de $1,31 \mathrm{~kg} / \mathrm{animal} / \mathrm{dia}$ e que os animais suplementados com farinha de varredura de mandioca e canola em grão a $0,2 \%$ do peso vivo apresentaram $1,53 \mathrm{~kg} / \mathrm{animal} / \mathrm{dia}$. No trabalho de Canto et al. (1997), os animais apresentaram ganho de $1,27 \mathrm{~kg} /$ animal/dia para animais terminados em pastagem de aveia consorciada com ervilhaca. $\mathrm{O}$ menor ganho de peso médio diário dos animais do presente estudo é reflexo da baixa capacidade de suporte ocorrida no final do experimento, o que interferiu no ganho de peso dos animais.

O ganho de peso vivo diário por hectare e o ganho de peso vivo total foram maiores $(\mathrm{P}<0,05)$ para o tratamento de aveia com suplementação energética $(4,00 \mathrm{~kg} / \mathrm{ha} / \mathrm{dia}$ e $244,27 \mathrm{~kg} / \mathrm{ha})$, seguido do tratamento de aveia consorciada com ervilhaca $(3,20 \mathrm{~kg} / \mathrm{ha} / \mathrm{dia}$ e $195,30 \mathrm{~kg} / \mathrm{ha})$, e o menor ganho ocorreu para o tratamento de aveia $(2,09 \mathrm{~kg} / \mathrm{ha} / \mathrm{dia}$ e $128,00 \mathrm{~kg} / \mathrm{ha})$. Segundo Rocha et al. (2003), esses dados quantificam o potencial de produção animal das diferentes alternativas de utilização da pastagem e, ainda, possibilitam verificar o retorno econômico de cada estratégia utilizada.

Observa-se que a suplementação proporcionou 90,83\% de incremento no ganho de peso vivo por hectare por dia, enquanto a consorciação com ervilhaca proporcionou aumento de $52,57 \%$ na produtividade diária por área, quando comparadas com a pastagem de aveia solteira. $\mathrm{O}$ incremento de mais de $50 \%$ na produção de bovinos com a utilização de leguminosas demonstra o potencial dessa alternativa de intensificação de pastagens cultivadas de inverno. Em regiões ou em anos em que o suplemento energético está com o custo elevado, a utilização de consorciações entre gramíneas e leguminosas temperadas mostra-se alternativa interessante. Rocha et al. (2003) observaram que, apesar de o tratamento com suplementação ter apresentado ganho de $19,5 \%$ por área, ele se mostrou menos eficiente economicamente em comparação com o consórcio entre aveia, azevém e trevo vesiculoso.

\section{CONCLUSÃO}

Os animais mantidos em pastagem de aveia branca suplementados com milho apresentaram melhor desempenho quando comparados com os animais mantidos apenas na pastagem de aveia branca. Já o consórcio de aveia branca com ervilhaca proporcionou desempenho intermediário, demonstrando ser uma boa alternativa na terminação de bovino de corte, principalmente em épocas em que a suplementação energética apresenta preços elevados.

\section{AGRADECIMENTOS}

A Fundação Araucária, pela bolsa de produtividade de Menezes, e ao $\mathrm{CNPq}$, pelo auxílio financeiro para condução do projeto.

\section{REFERÊNCIAS}

ALMEIDA, E.X.; MARASCHIN, G.E.; HARTHMANN, O.E.L. et al. Oferta de forragem de capim-elefante anão 'Mott' e o rendimento animal. Rev. Bras. Zootec., v.29, p.1288-1295, 2000.

ALVES, D.D. Crescimento compensatório em bovinos de corte. Rev. Port. Cienc. Vet., v.98, p.61-67, 2003.

AGUINAGA, A.A.Q.; CARVALHO, P.C.F.; ANGHINONI, I. et al. Produção de novilhos superprecoces em pastagem de aveia e azevém submetida a diferentes alturas de manejo. Rev. Bras. Zootec., v.35, p.1765-1773, 2006.

BARCELLOS, A.O.; RAMOS, A.K.B.; VILELA, L. et al. Sustentabilidade da produção animal baseada em pastagens consorciadas e no emprego de leguminosas exclusivas, na forma de banco de proteína, nos trópicos brasileiros. Rev. Bras. Zootec., v.37, supl esp., p.51-67, 2008.

CANTO, M.W.; RESTlE, J.; QUADROS, F.L.F. et al. Produção animal em pastagens de aveia (Avena strigosa Schreb.) adubada com nitrogênio ou em mistura com ervilhaca (Vicia sativa L.). Rev. Bras. Zootec., v.26, n.2, p.396-402, 1997.

CARTAS climáticas do Paraná: temperatura. Londrina, PR: Instituto Agronômico do Paraná, 2014. Disponível em: <http://www.iapar.br/modules/ conteudo/conteudo.php?conteudo $=860>$. Acessado em $06 / 03 / 2015$ 
DAll'AGNOL, M.; SCHEFFER-BASSO, S.M Utilização de recursos genéticos de leguminosas para ruminantes. In: REUNIÃO ANUAL DA SOCIEDADE BRASILEIRA DE ZOOTECNIA, 41., 2004, Campo Grande. Anais... Campo Grande: Sociedade Brasileira de Zootecnia, 2004. p.115-128.

DIERKING, R. M.; KALLENBACH, R. L.; GRUN, I.U. Effect of forage species on fatty acid content and performance of pasture-finished steers. Meat Sc., v.85, p.597-605, 2010.

FRAME, J.; NEWBOULD, P. Agronomy of white clover. Adv. Agron., v.40, p.1-88, p.237-247, 1986.

GOERING, H.K.; VAN SOEST, P.J. Forage fiber analysis (apparatus, reagents, procedures and some applications). Washington D.C.: Agricultural Research Service, 1970. 19 p. (Agriculture Handbook, 379).

GRISE, M.M.; CECATO, U.; MORAES,A.; et al. Avaliação do sesempenho animal e do pasto na mistura aveia IAPAR 61 (Avena strigosa Schreb) e ervilha forrageira (Pisum arvense L.) manejada em diferentes alturas. Rev. Bras. Zootec., v.31, p.10851091, 2002.

HARRIS, W. Pasture as an ecosystem. In: LANGER. R.H.M. (Ed.). Pastures: their ecology and management. Auckland: Oxford University Press, 1990. Chap.3, p. 75-131.

HELLBRUGGE, C.; MOREIRA, F.B. ; MIZUBUTI, I.Y. et al. Desempenho de bovinos de corte em pastagem de azevém (Lolium Multiflorum) com ou sem suplementação energética. Sem.: Ciênc. Agr., v.29, p.723-730, 2008.

LAIDLAW, A.S.; TEUBER, N. Temperate forage grass-legume mixtures: advances and perspectives. In: INTERNATIONAL GRASSLAND CONGRESS, 19., 2001. Proceedings... São Paulo: Brazilian Society of Animal Husbandry, 2001. p.85-92.

MACARI, S.; ROCHA, M.G.; RESTLE, J. et al. Avaliação da mistura de cultivares de aveia preta (Avena strigosa Schreb) com azevém (Lolium multiflorum Lam.) sob pastejo. Cienc. Rural, v.36, p.910-915, 2006.

MENEZES, L.F.G.; SEGABINAZZI, L.R.; BRONDANI I.L., et al. Silagem de milho e grão de sorgo como suplementos para vacas de descarte terminadas em pastagem cultivada de estação fria. Arq. Bras. Med. Vet. Zootec. v.61, p.182-189, 2009.

MOREIRA, F.B.; PRADO, I.N.; MATSUSHITA, N.E.S.M. et al. Desempenho animal e características de carcaça de novilhos terminados em pastagem de aveia preta, com ou sem suplementação energética. Acta Sci.. Anim. Sci., v.27, p.469-473, 2005.
MOTT, G.O. Grazing pressures and the measurement of pastures production. In: INTERNATIONAL GRASSLAND CONGRESS, 8., 1960, Reading. Proceedinga .... Reading: [s.n.], 1960. p.606-611.

MOTT, G.O.; LUCAS, H.L. The design conduct and interpretation of grazing trials on cultivated and improved pastures. In: INTERNATIONAL GRASSLAND CONGRESS, 6, 1952. Proceedings... Pennsylvania. State College Press, 1952. p.1380-1395.

PAULINO, M.F.; MORAES, E.H.B.K.; ZERVOUDAKIS, J.T. et al. Fontes de energia em suplementos múltiplos de auto-regulação de consumo na recria de novilhos mestiços em pastagens de Brachiaria decumbens durante o período das águas. Rev. Bras. Zootec., v.34, p.957-962, 2005.

PAULINO, V.T.; CARVALHO, D.D. Pastagens de Inverno. Rev. Cient. Eletron. Agron., v.3, p. 1-6, 2004.

POSSENTI, J.C.; GOUVEA; A.; MARTIN, T. et al. Distribuição da precipitação pluvial em Dois Vizinhos, Paraná, Brasil. In: Seminário de Produção Agropecuária, 1. 2007, Dois Vizinhos, PR. Anais... Dois Vizinhos, PR: UTFPR, 2007. p.1-3.

ROCHA, M.G.; RESTLE, J.; FRIZZO, A. et al. Alternativas de utilização da pastagem hibernal para recria de bezerras de corte. Rev. Bras. Zootec., v.32, p.383-392, 2003.

SANTOS, G.T., CAVAliERI, F.L.B., MODESTO, E.C. Recentes avanços em nitrogênio não protéico na nutrição vacas leiteiras. In: SINLEITE - NOVOS CONCEITOS EM NUTRIÇÃO, 2., 2001, Lavras. Anais... Lavras: Universidade Federal de Lavras, 2001. p.225-248.

SISTEMA brasileiro de classificação de solos. Rio de janeiro: EMBRAPA / Centro Nacional de Pesquisa de Solos., 2006. 412p.

SILVA, D.J.; QUEIROZ, A.C. Análise de alimentos e métodos químicos e biológicos. 3.ed. Viçosa, MG: Universidade Federal de Viçosa, 2006. 235p.

USER'S guide: statistics, versão 8.1. 4.ed., v.2, Cary: SAS Institute, 2000. (CD-ROM).

WEISS, W.P.; CONRAD, H.R.; ST. PIERRE, N.R. A theoretically based model for predicting total digestible nutrient values of forages and concentrates. Anim. Feed Sci. Technol., v.39, p.95-110, 1992.

WILM, H.G.; COSTELLO, D.F.; KLIPPLE, G.E. Estimating forage yield by the double-sampling methods. J. Am. Soc. Agron., v.36, p.194- 203, 1944.

WRIGHT, A., Effect of forage type and corn supplementation on animal performance and meat quality. 2013. 84f. Theses (Master of Science) Graduate School of Clemeson University. 